\title{
Bleeding Diathesis
}

National Cancer Institute

\section{Source}

National Cancer Institute. Bleeding Diathesis. NCI Thesaurus. Code C115221.

A coagulation disorder characterized by a tendency for excessive bleeding. 